\title{
REDES NEURAIS ARTIFICIAIS NA PREDIÇÃO DO PREÇO FUTURO DE FECHAMENTO DE PAPÉIS COM ALTA E BAIXA VOLATILIDADE NEGOCIADOS NA BOVESPA E NA BOLSA DE VALORES DE NOVA IORQUE
}

\author{
Theodoros Barsante Papadopoulos \\ Facci/Funcesi \\ theodoros.barsante@gmail.com \\ Fabricio Roulin Bittencout \\ Facci/Funcesi \\ fabriciorb@gmail.com \\ Felipe Lacerda Diniz Leroy \\ Facci/Funcesi \\ felipe.leroy@funcesi.br \\ Thaís Cotta Barbosa Reis \\ Facci/Funcesi \\ thais_cotta@yahoo.com.br \\ Patrícia Carla de Brito Neves \\ Facci/Funcesi \\ patriciacb.neves@gmail.com
}

\begin{abstract}
Resumo
É cada vez mais evidente a necessidade da predição de valores nos mercados financeiros e seu ganho frente aos concorrentes. Esse trabalho tem por objetivo analisar o grau de predição das RNAs aplicadas na predição de valores do mercado de ações. Essa é uma pesquisa quantitativa, do tipo explicativa e experimental. O universo é formado por todo o histórico dos valores das ações PETR4, VALE5, OGXP3, GS e JPM. Os dados foram coletados através do software Economática e foram tratados através de simulações geradas pelo software Matlab e, por fim, analisados através da estatística descritiva. A pesquisa limita-se na predição de valores das ações que foram utilizadas na amostra. Os papéis foram identificados através da análise de sua volatilidade. Foram selecionados papéis com baixa e com alta volatilidade, com comportamentos conservadores e agressivos, a fim de testar o grau de predição da RNA quando aplicada em ambas as situações. Esses dados foram normalizados em um intervalo entre 0.2 e 0.8 para uso na RNA. Os resultados gerados pela simulação da RNA foram analisados e o grau de ajuste das predições foi encontrado utilizando o cálculo da diferença entre a variância do real pela variância do observado. $\mathrm{O}$ grau de predição do preço futuro de fechamento de papéis com alta e baixa volatilidade negociados na Bovespa e na Bolsa de Valores de Nova Iorque usando RNA é significativo. Portanto, de acordo com os resultados atingidos, a RNA aplicada na predição de valores de ações com alta e baixa volatilidade é possível e possui um resultado satisfatório.
\end{abstract}

Palavras chave: Mercado de ações. Redes neurais artificiais. 


\section{INTRODUÇÃO}

Com o crescimento dos mercados financeiros e com as mudanças nos valores dos ativos, fica cada vez mais evidente a necessidade da utilização de métodos eficientes pelos profissionais da área de finanças para analisar o comportamento desses ativos e nortear os investimentos no mercado de ações. Uma série de abordagens matemáticas vêm sendo utilizadas na predição do comportamento desses ativos, incluindo os sistemas inteligentes.

O mercado de ações é um ambiente de riscos, onde existe a possibilidade de perdas resultantes da flutuação dos valores dos papéis das organizações. Alguns desses riscos podem ser mapeados, outros não. Nem sempre é possível identificar o que pode influenciar o preço de uma ação. O cenário escolhido para predição de valores foi o mercado de ações. Prever o valor futuro de uma ação não é uma tarefa fácil, e para isso é necessário entender o comportamento dessa ação e, em seguida, com base nesse conhecimento adquirido, estimar o seu valor futuro, com uma margem de erro satisfatória.

Duas bolsas de valores foram selecionadas para serem utilizadas na pesquisa: a Bovespa e a Bolsa de Valores de Nova Iorque. As ações selecionadas da Bovespa foram a PETR4, a VALE5 e a OGXP3, enquanto na Bolsa de Valores de Nova Iorque as ações selecionadas foram a GS e JPM. É preciso buscar de uma fonte confiável os dados históricos das ações. Um software que possui um banco de dados confiável contendo essas informações é o Economática [3]. Com ele foi possível buscar todo o histórico das cinco ações estudadas nesse trabalho.

A Rede Neural Artificial (RNA) é a abordagem utilizada nessa pesquisa. Ela é uma das habituais técnicas da inteligência artificial aplicadas na predição de séries temporais. As RNAs são técnicas computacionais que apresentam um modelo matemático baseado na estrutura neural de organismos inteligentes. A RNA foi utilizada nessa pesquisa por se destacar na capacidade de aprendizado e generalização. As RNAs são técnicas utilizadas nas mais diversas áreas, como por exemplo no reconhecimento de padrões em composições musicais, otimização de recursos, robótica e na previsão de séries temporais [2].

Para avaliar a RNA na predição dos valores de fechamento de papéis negociados no mercado de capitais, foram selecionadas ações com baixa e alta volatilidade. Com base nos resultados é possível identificar não só a aplicação das RNAs na predição dos valores das ações, mas também a aplicação da RNA na previsão de ações que possuem comportamentos mais agressivos.

Existem diversos motivos para se buscar prever o comportamento dos papéis negociados no mercado financeiro. Um deles, e talvez o principal, é o lucro que pode ser obtido através da valorização de um papel em determinado período de tempo. A tarefa mais delicada no mercado de capitais é a previsão do comportamento desses papéis, que leva o investidor a obter lucro, ou prejuízo, com o capital investido. Quem deter o poder da predição desses valores terá a oportunidade de antever, em uma situação normal de negociação, o comportamento dos papéis que deseja negociar e assim definir o rumo de seu investimento.

Diversos estudiosos procuram prever o comportamento dos papéis negociados na Bovespa, inclusive utilizando outros modelos para predição de valores, como por exemplo, o modelo ARIMA. A verdade é que não há uma fórmula mágica para prever o mercado de ações. Diversas questões afetam as altas e as baixas dos preços das ações como, por exemplo, a saúde financeira da organização, descobertas de novas fontes capazes de alavancar suas negociações, acordos entre grandes concorrentes e fusões empresariais. Essas mudanças podem ocorrer de forma gradual ou em picos acentuados.

A previsão desses valores, com uma taxa mínima de erro, é o grande desafio dos investidores, pois assim será possível trabalhar, de forma mais segura, os valores que são investidos no mercado de capitais. Munido dessa informação, o investidor ou agente de 
investimentos, terá uma oportunidade de maximizar o lucro obtido com a negociação dos papéis, pois terá uma ideia aproximada de quando e onde investir de forma segura e rentável.

Considerando o cenário atual e passado do mercado de capitais, a previsão de valores pode trazer um peso diferenciado para análise do comportamento de uma ação, indicando uma possível alta ou baixa do papel analisado. A grande questão analisada pelos estudiosos do mercado de capitais é em qual época deve-se vender ou comprar determinada ação a fim de maximizar o lucro do investimento? Para tal previsão, será utilizada uma Rede Neural Artificial (RNA), que é uma estrutura computacional composta por um modelo matemático inspirado na estrutura neural de organismos inteligentes, que possuem capacidade de adquirir conhecimento através do aprendizado.

Por fim, tem-se como principal objetivo deste trabalho analisar o grau de predição do preço futuro de fechamento de papéis com alta e baixa volatilidade negociados na Bovespa e na Bolsa de Valores de Nova Iorque usando Redes Neurais Artificias (RNA).

\section{REDES NEURAIS ARTIFICIAIS}

A Rede Neural Artificial (RNA) é uma técnica da inteligência artificial capaz de produzir conhecimento e determinar o comportamento de um conjunto de dados através de uma série de treinamentos e simulações. Essa capacidade de processar e extrair conhecimento através do aprendizado tem se mostrado eficiente na solução de problemas de um grau de complexidade maior através da computação convencional [2].

Redes Neurais Artificiais são estruturas computacionais compostas por um modelo matemático construído inspirado na estrutura neural de organismos inteligentes, capazes de adquirir conhecimento por meio da experiência. Uma rede neural artificial pode ser composta por milhares de unidades de processamento; enquanto o cérebro de um mamífero, por exemplo, pode conter bilhões de neurônios [8].

Estruturas neurais artificias são responsáveis pelo processamento da informação nas RNA's. São realizadas de maneira concomitante e são repartidos por componentes processadores relativamente simples. O neurônio proposto por McCulloch e Pitts (MCP) em 1943 é responsável por formar cada componente processador [16].

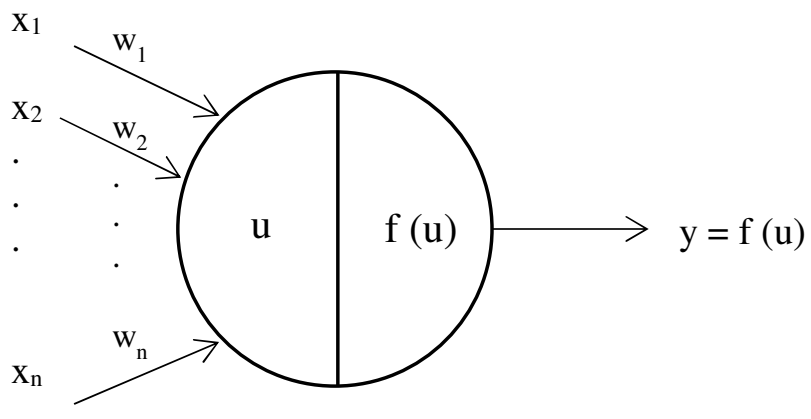

FIGURA 1: Modelo do neurônio MCP Fonte: [16]

Como visto na FIG. 1, o neurônio é composto por três elementos básicos. O primeiro é o conjunto de sinapses, representado pelos valores de $x 1, x 2, \ldots, x n$, que nada mais é do que a região de contato entre dois neurônios. Em seguida o somatório (u), responsável pela soma de todas as entradas multiplicadas pelos pesos $W 2, \ldots, W n$. Por fim, a função de ativação $f(u)$, cujo o objetivo é aproximar a função localmente por uma função afim, ou seja, um hiperplano 
[16] [1].

Para [8] as RNA's têm a capacidade de solucionar qualquer problema de aproximação de função contínua, não importando a quantidade de variáveis. Para tal, se faz necessário a definição do número de entradas e saídas relacionadas diretamente aos dados. Feito isso, para que se obtenha um bom desempenho, deve-se definir a quantidade ideal de neurônios na camada intermediária (escondida). Para isso, deve-se levar em consideração que a quantidade de neurônios da camada escondida está diretamente ligada à complexidade do problema, ou seja, quanto mais complexo for o problema, mais neurônios serão necessários a fim de se obter um bom desempenho da RNA.

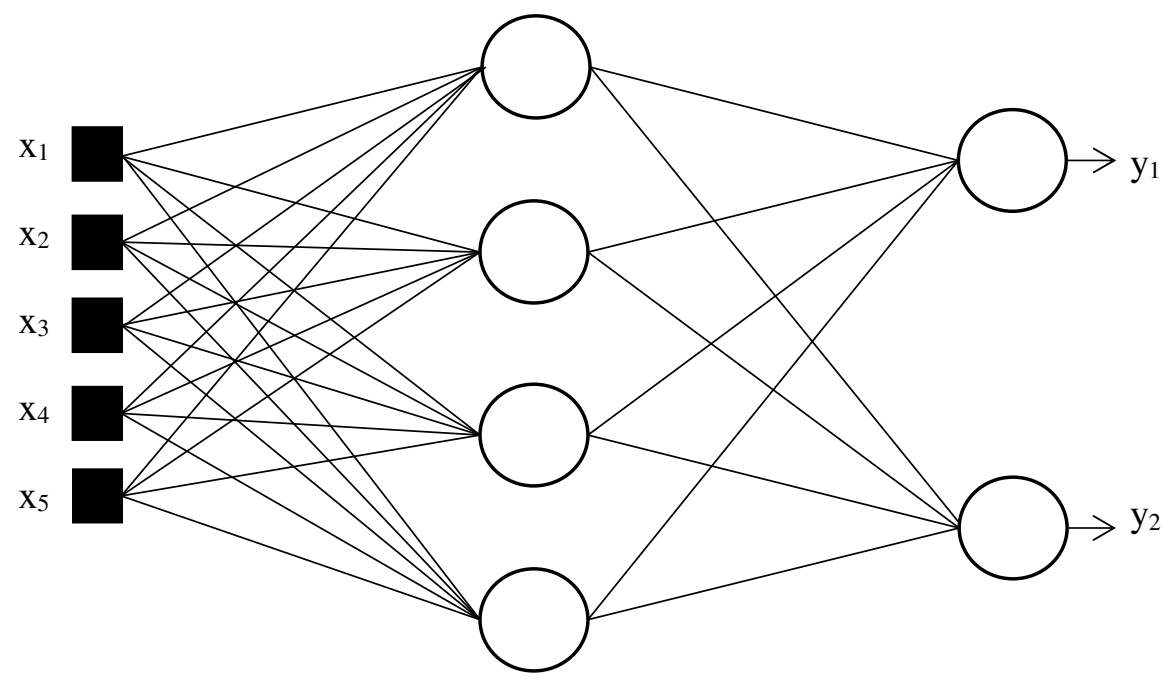

FIGURA 2: RNA feed-forward totalmente conectada Fonte:[16]

Na FIG. 2, [16] apresenta a estrutura de uma rede feed-forward com cinco entradas, representadas por $\mathrm{x} 1, \mathrm{x} 2, \mathrm{x} 3, \mathrm{x} 4$ e $\mathrm{x} 5$, duas saídas, representadas por y1 e y2, e quatro neurônios que compõem a camada intermediária. Essa configuração é capaz de solucionar problemas de regressão, classificação ou ainda de predição.

Segundo [8] uma RNA pode possuir várias camadas e dependendo da conexão entre elas obtêm-se estruturas diferentes. A forma como estas conexões estão organizadas está diretamente relacionada com o algoritmo de aprendizagem que deverá ser utilizado para o treinamento da RNA. Uma RNA com mais de uma camada é do tipo perceptron multicamadas, também conhecida como Multilayer Perceptron (MLP).

Para que seja possível a realização do processo de aprendizagem, é utilizado um algoritmo de treinamento. Esse algoritmo modifica os pesos sinápticos da RNA de forma sistemática, com o objetivo de atingir aquilo que foi estipulado na fase de concepção. O mais popular dos algoritmos, no que tange o treinamento de redes multicamadas é o backpropagation, esse algoritmo é do tipo de aprendizado supervisionado. Seu trabalho é feito aos pares, onde existem entrada e saída desejada, a partir dos quais ajustam-se os pesos da rede, utilizando-se de um método de correção de erros [8][2].

Para [8] o algoritmo de Kenneth Levenberg com aperfeiçoamento de Donald Marquardt, comumente conhecido com Algoritmo de Levenberg-Marquardt (LM) é um método de otimização. Segundo [15] Levenberg-Marquardt é atualmente o algoritmo de otimização mais utilizado nos projetos de RNA's. Isso porque ele tem uma performance elevada na solução de diversos problemas. Para [8] ele é um algoritmo de destaque 
principalmente pelo ajuste célere e eficaz dos pesos.

Para [15] o algoritmo LM tem como objetivo a resolução, de forma iterativa, de problemas de minimização de funções não-lineares, através do método de mínimos quadrados. Sua base é o algoritmo do gradiente descendente e o método iterativo de GaussNewton.

Por fim, a retropropagação tem grande valia no processo de aprendizado e ajuste de erro, pois a partir dela, a rede pode realizar o treinamento sem intervenção humana, o que acelera o processo e reduz a margem de erro. É perceptível ainda que o algoritmo de LM é considerado pelos autores o algoritmo de melhor desempenho para o treinamento das redes, sendo a escolha que melhor se ajusta ao que propõe o treinamento das RNA's desta pesquisa.

\section{MERCADO DE CAPITAIS}

O mercado de capitais é um sistema responsável pela distribuição de valores mobiliários, que proporciona liquidez aos títulos de emissão de empresas e possibilita o processo de capitalização. Ele é composto pelas bolsas de valores, sociedades corretoras e outras instituições financeiras que são devidamente autorizadas a agir nesse mercado.

Com o objetivo de viabilizar e disponibilizar recursos entre partes interessadas em negociar, o mercado de capitais reúne instituições e instrumentos a fim de proporcionar um ambiente de negociações de títulos e valores imobiliários, isto é, seu objetivo é tornar viável a capitalização das empresas e prover liquidez aos seus títulos, com a distribuição sistêmica de valores mobiliários. Seu surgimento deu-se no momento em que o mercado de crédito deixou de assegurar recursos com prazos curtos e exigibilidades adequadas [14].

As ações surgiram na Inglaterra no ano de 1553. A empresa Muscovy Company, como forma de captar o montante de 6.000 libras para enviar mercadorias até a Rússia por via fluvial, recebeu de cada mercador uma parte, ou share, daquele montante, e como retorno desse investimento, eles tinham o direito de auferir o percentual relativo à sua parte do lucro do envio ou perdê-lo caso houvesse prejuízo [14].

A ação então pode ser traduzida como a menor parte do capital social de uma organização separada por ações. O local onde essas ações são negociadas é conhecido como bolsa de valores, que são organizações sem fins lucrativos, derivadas de esforços das corretoras de valores a fim de prover um ambiente físico para o mercado de ações [4].

O valor de uma ação é derivado das condições do mercado, como oferta e procura, condições estas, espelho da saúde econômica da organização e do País. De modo geral, elas são as expectativas dos agentes econômicos com a República e consequentemente o rumo das empresas de capital aberto [4].

Como a negociação no mercado de ações é diária, ocorrendo apenas em dias úteis, e funciona de forma eletrônica, o preço das ações oscila em duas situações: se há muitos compradores, o preço da ação tende a subir; do contrário, ou seja, quando há muitos investidores vendendo essas ações, o preço dessa ação tende a cair. Essa é a lei da oferta e da procura [4].

A bolsa com maior expressão no cenário nacional era a Bolsa de Mercadorias e Futuros (BM\&F) até que houve a fusão em maio de 2008 com a Bolsa de Valores de São Paulo (Bovespa), que até então era a bolsa oficial do Brasil, dando origem a uma nova instituição denominada BM\&FBovespa [14].

Segundo [10], volatilidade nada mais é do que o ato de medir a dispersão dos retornos de um título ou ainda de um índice de mercado, tal como a medição do maior e menor preço de uma ação em um determinado período, o grau médio da variação de cotações, variância e a medida de volatilidade comparada.

A decisão de abrir o capital na bolsa de valores é da organização. Após determinar a abertura de capital e decidir por utilizar a bolsa como meio de negociações dos papéis, as 
bolsas de valores podem definir critérios para aceitação dessa organização, e isso varia de caso para caso [4].

A BOVESPA é o mercado de ações do Brasil e reúne os papéis das principais organizações brasileiras de capital aberto, como por exemplo, a Vale, a Petrobrás, a Cemig, entre outras. Milhões de papéis são negociados entre os mais diversos investidores diariamente, por preços definidos pela lei da oferta e da demanda [14].

O Índice Bovespa (IBOVESPA) é o principal indicador do mercado de ações do mercado brasileiro. Ele afere a lucratividade dos papéis pertencentes a carteira do investidor, além de descrever o comportamento do mercado de ações.

Uma ação possui uma cotação, ou seja, seu preço em bolsa. Existem algumas outras terminologias empregadas, como por exemplo, o valor nominal, que é valor estipulado no estatuto da organização, ou ainda o valor patrimonial, que representa o valor líquido da empresa dividido pela quantidade de papéis emitidos [14].

O valor que os compradores dos papéis aceitam pagar e os vendedores receber naquele determinado momento chama-se valor de mercado. Para saber o seu valor de mercado estipulado em bolsa basta consultar seu prospecto de lançamento.

Para obter rendimento com as ações o investidor pode receber benefícios na forma de proventos, com o direito de preferência na aquisição de novas ações, ou ainda na movimentação de preços do mercado de ações. Na maioria das vezes, os ganhos vêm com o lucro da venda dos papéis [14].

Outra forma de obtenção de valores com as ações são os dividendos. Dividendo é a distribuição de parte dos lucros líquidos de uma organização, pagos em moeda, aos seus acionistas. Estabelecido em lei, a organização deve distribuir $25 \%$ de seu lucro líquido do exercício entre os seus acionistas [4].

As ações criam diversas formas de lucrar com as suas transações, desde a compra e venda simplesmente dos papéis, aguardando o momento certo de alta para efetivar uma venda, até os valores agregados à elas, como, por exemplo, o recebimento de dividendos das organizações.

\section{METODOLOGIA}

Para este estudo empregou-se a abordagem quantitativa e tipo de pesquisa explicativa através de pesquisa experimental, por permitir a análise de um conjunto de dados representando os valores passados de fechamento dos papéis negociados na Bovespa e na Bolsa de Valores de Nova Iorque e, em seguida, simular seu preço futuro de fechamento, prevendo o seu comportamento com base em análises passadas, sendo possível chegar a valores próximos da realidade, e com um grau mínimo de ajuste [7].

Compreende-se que o universo desta pesquisa foram os valores históricos dos papéis PETR4, VALE5 e OGXP3, negociados na Bovespa e dos papéis GS e JPM, negociados na Bolsa de Valores de Nova Iorque. A amostra deste estudo é formada pelos valores de fechamento dos papéis VALE5, PETR4, OGX3 negociados na Bovespa e dos papéis JPM e GS, negociados na Bolsa de Valores de Nova Iorque, no período de julho de 2008 até agosto de 2013. O critério de amostragem foi o não probabilístico por tipicidade e a escolha desse critério de amostragem deu-se pelo fato dos papéis analisados possuírem alta e baixa volatilidade [12].

Os dados dessa pesquisa foram coletados na base de dados do software Economatica e por meio de simulações no software Matlab. Para o tratamento dos dados foi utilizada a estatística descritiva. As medidas estatísticas utilizadas nessa pesquisa foram a média aritmética e a variância [7]. 


\section{ANÁLISE DOS DADOS}

A escolha por quais ações devem ser trabalhadas na pesquisa deu-se pela análise da sua volatilidade. Segundo [10], volatilidade nada mais é do que o ato de medir a dispersão dos retornos financeiros de títulos ou índices de mercado. Foram escolhidas ações mais conservadoras, ou seja, com baixa volatilidade, e ações mais arriscadas, portanto consideradas ações de alta volatilidade. Para análise da solução de predição de valores tanto no cenário interno, quanto no mercado internacional, foram escolhidas as bolsas de valores do estado de São Paulo (Bovespa) e a bolsa de valores da cidade de Nova Iorque. Para a Bovespa, foram selecionadas as ações preferenciais VALE5 e PETR4, e a ação ordinária OGXP3. Na Bolsa de Valores de Nova Iorque foram selecionadas duas ações com alta volatilidade: a GS e a JPM.

Após a identificação dos papéis que serão utilizados faz-se necessário obter os valores das ações a partir de uma fonte confiável, pois qualquer variação nesses valores poderia inviabilizar o resultado produzido [13]. Para tal, os dados foram coletados através do software Economatica, que é uma ferramenta composta por diversos módulos utilizados na análise de papéis e de fundos de investimento [3]. Ele possui uma base de dados amplamente preenchida, além de ser utilizado por analistas de corretoras, bancos, universidades, entre outros.

Foram utilizados os valores de fechamento do período de 01 de julho de 2008 até 21 de agosto de 2013. As ações negociadas na Bovespa possuem 269 registros e as ações negociadas na Bolsa de Valores de Nova Iorque possuem 290 registros. A quantidade de registros é diferente, apesar do período ser o mesmo, pela quantidade de dias de pregão, pois o funcionamento das bolsas varia de acordo com cada país.

Segundo [17], a etapa que antecede o treinamento e a simulação de uma RNA consiste na normalização dos dados de entrada e saída. Para a RNA utilizada nessa pesquisa, a etapa de pré-processamento consiste na normalização desses valores no intervalo de 0 a 1 . A normalização consiste em harmonizar escalas, o que na realidade corresponde em adaptar as escalas que possuem grandezas distintas. Na função sigmoide, os valores dentro do intervalo de 0 e 1 são infinitos, portanto é aconselhável reduzir esse intervalo utilizado na normalização dos dados para 0.2 e 0.8 , pois são valores mais suaves no intervalo de 0 e 1 e auxiliam a convergência durante a etapa de treinamento. A normalização e desnormalização ocorreram utilizando as seguintes equações:

$$
\begin{aligned}
& \text { Eq. 01: } f^{\text {a }}(L o)=L n=(L o-L \min ) /(L \max -L \min ) \\
& \text { Eq. 02: } f^{\mathrm{b}}(L n)=L o=L n * L \max +(1-L n) * L \min \\
& \text { Eq. 03: } L \min =(4 * \text { LimiteInf }- \text { LimiteSup }) / 3 \\
& \text { Eq. 04: } L \max =(\text { LimiteInf. }-0,8 * L \min ) / 0.2
\end{aligned}
$$

Onde: $L o$ é o valor a ser normalizado, $L n$ é o valor normalizado; $L$ min e $L$ max são os valores mínimos e máximos respectivamente dentre os valores das variáveis, LimiteInf e LimiteSup são os valores mínimos e máximos do conjunto de dados original.

A RNA projetada para este trabalho foi uma rede multilayer perceptron (MLP) com cinco entradas, onze neurônios na única camada escondida e uma saída. Esta estrutura será a mesma para treinamento e simulação de cada uma das ações separadamente. Cada entrada representa um dia de pregão, logo as cinco entradas da rede recebem os cinco últimos valores obtidos no fechamento da bolsa de valores para a ação em questão, e a saída representa a previsão do valor futuro de fechamento da ação. Para definir a quantidade de neurônios na camada escondida da RNA, foi aplicado o teorema apresentado por Hecht-Nielsen (1989) e Hecht-Nielsen (1990) citado por [11], no qual diz que a camada escondida deve ser composta por $(2 n+1)$ neurônios, sendo $n$ o número de entradas da RNA. 
A RNA foi implementada no software Matlab, na versão R2012a, com auxílio da sua toolbox NNTOOL. O algoritmo de treinamento da RNA utilizado nessa pesquisa é o Levenberg Marquardt, esse algoritmo é invocado pela função pertencente ao Matlab nomeada TRAINLM.

Foram realizadas duas etapas de simulações. Na primeira etapa, a RNA recebeu $80 \%$ da amostra como dados de treinamento e $20 \%$ da amostra como dados de simulação. Na segunda etapa, a RNA recebeu toda a amostra como dados de treinamento e os cinco últimos dias de pregão que antecederam o dia a ser previsto foram utilizados como entrada para a simulação dessa etapa, o objetivo foi prever o valor do dia seguinte utilizando a RNA em uma situação real. Em ambas as etapas, os dados gerados pela saída da RNA foram comparados com os dados registrados no histórico da ação, e através da diferença da variância do real pela variância do observado (saída da RNA) foi possível obter o grau de predição, afinal, segundo [5], quanto mais próximo de zero é o valor do resultado encontrado, mais homogêneas serão as distribuições dos valores.

Foram realizadas 10 (dez) simulações para cada papel analisado nessa pesquisa. $\mathrm{O}$ objetivo foi verificar o desempenho da RNA e analisar o pior e o melhor resultado encontrado. Essas simulações foram realizadas com os parâmetros idênticos da RNA.

\section{TABELA 1}

Diferença da variância dos valores reais e observados (saída da RNA) das ações analisadas que obtiveram o melhor grau de ajuste

\begin{tabular}{c|cccc}
\hline Ação & Variância do Real & Variância do Observado & Diferença \\
\hline PETR4 & 3,136943537 & 3,115080788 & 0,021862749 \\
VALE5 & 11,26465983 & 11,24134794 & 0,023311898 \\
OGX3 & 4,211482969 & 4,20250106 & 0,008981909 \\
GS & 518,4765326 & 519,7157656 & 1,239233006 \\
JPM & 45,24811519 & 46,96398466 & 1,715869468 \\
\hline
\end{tabular}

Fonte: Elaborado pelo próprio autor

A TABELA 1 apresenta a variância dos valores reais e a variância dos valores observados (valor da saída da RNA) de cada ação utilizada na pesquisa, além da diferença entre eles. Os valores apresentados nessa tabela são os valores que obtiveram o melhor grau de ajuste. É possível observar na TABELA 1 que a diferença da variância nos valores das ações GS e JPM é superior quando comparada aos demais papéis analisados. Isso se dá pelo fato dessas ações serem de alta volatilidade, e o preço dos papéis ser elevado, portanto qualquer variação de valor é expressiva.

\section{TABELA 2}

Diferença da variância dos valores reais e observados (saída da RNA) das ações analisadas que obtiveram o pior grau de ajuste

\begin{tabular}{c|cccc}
\hline Ação & Variância do Real & Variância do Observado & Diferença \\
\hline PETR4 & 3,136943537 & 3,800743078 & 0,663799541 \\
VALE5 & 11,26465983 & 11,08372806 & 0,18093177 \\
OGX3 & 4,211482969 & 9,147852924 & 4,936369955 \\
GS & 518,4765326 & 526,5335166 & 8,056983982 \\
JPM & 45,24811519 & 32,39374595 & 12,85436924 \\
\hline
\end{tabular}

Fonte: Elaborado pelo próprio autor 
A TABELA 2 apresenta a variância dos valores reais e a variância dos valores observados (valor da saída da RNA) de cada ação utilizada na pesquisa, além da diferença entre eles. Os valores apresentados nessa tabela são os valores que obtiveram o pior grau de ajuste. Com base nos resultados apresentados na TABELA 2 é possível identificar as ações com alta volatilidade. Essa diferença evidente no pior resultado é reflexo dessa alta volatilidade, e esse valor é relativamente menor nas ações de baixa volatilidade, mesmo no pior resultado da RNA.

\section{TABELA 3}

Diferença da variância dos valores reais e observados (saída da RNA) da predição diária

\begin{tabular}{c|cccc}
\hline Ação & Variância do Real & Variância do Observado & Diferença \\
\hline PETR4 & 0,440853118 & 0,46336633 & 0,022513212 \\
VALE5 & 2,673304946 & 2,807531265 & 0,134226319 \\
OGX3 & 0,004936559 & 0,005047473 & 0,000110914 \\
GS & 9,743818495 & 8,704684326 & 1,039134169 \\
JPM & 1,989412258 & 1,429286578 & 0,56012568 \\
\hline
\end{tabular}

Fonte: Elaborado pelo próprio autor

A TABELA 3 apresenta a variância dos valores reais e a variância dos valores observados (valor da saída da RNA) de cada ação utilizada na pesquisa durante o período de 31 dias em que a RNA foi simulada em um cenário real, além da diferença entre eles. Com o objetivo de simular a utilização da RNA em um cenário real e analisar seu desempenho, foram realizadas simulações diárias dos cinco papéis utilizados nessa pesquisa. Essas simulações iniciaram-se em 10 de julho de 2013 e encerraram-se em 21 de agosto de 2013, totalizando 31 simulações acompanhadas diariamente, em um cenário real.

\section{TABELA 4}

Comparação da simulação com dados históricos com a predição diária entre 10/07/13 e 21/08/13

\begin{tabular}{c|c|c}
\hline Ação & $\begin{array}{c}\text { Diferença entre variância do real } \\
\text { e observado na simulação com dados } \\
\text { históricos }\end{array}$ & $\begin{array}{c}\text { Diferença entre variância do real } \\
\text { e observado na predição diária entre } \\
\mathbf{1 0 / 0 7 / 1 3 ~ e ~ 2 1 / 0 8 / 1 3}\end{array}$ \\
\hline PETR4 & 0,021862749 & 0,022513212 \\
VALE5 & 0,023311898 & 0,134226319 \\
OGX3 & 0,008981909 & 0,000110914 \\
GS & 1,239233006 & 1,039134169 \\
JPM & 1,715869468 & 0,56012568 \\
\hline
\end{tabular}

Fonte: Elaborado pelo próprio autor

Comparando-se a terceira coluna da TABELA 1 com a terceira coluna da TABELA 3, tem-se a TABELA 4. Pode-se observar que o desempenho da RNA na predição diária entre 10/07/13 e 21/08/13 foi melhor, exceto para a ação PETR4 com uma suave diferença.

Na TABELA 5, pode-se constatar o bom desempenho da RNA durante o período de 31 dias em que a RNA foi simulada em um cenário real. Neste período de teste as RNA's apresentaram uma boa previsão dos valores de fechamento das ações selecionadas para esta pesquisa, comprovando que as RNA's aprenderam o comportamento das ações e demonstrando ser um bom indicador de alta ou de baixa no valor das ações usadas nesta pesquisa. Para cada ação na TABELA 5, pode-se observar que a saída da RNA é bem 
próxima do valor real negociado na bolsa de valores. A Fig. 03 apresenta graficamente cada uma das ações mostradas na TABELA 5.

TABELA 5

Comparação dos valores diários reais e previstos pela RNA no dia anterior durante o período de 31 dias

\begin{tabular}{|c|c|c|c|c|c|c|c|c|c|c|}
\hline & \multicolumn{2}{|c|}{ PETR4 } & \multicolumn{2}{|c|}{ VALE5 } & \multicolumn{2}{|c|}{ OGXP3 } & \multicolumn{2}{|c|}{ GS } & \multicolumn{2}{|c|}{ JPM } \\
\hline Data & $\begin{array}{l}\text { Valor } \\
\text { Real } \\
\text { (R\$) }\end{array}$ & $\begin{array}{l}\text { Saída } \\
\text { RNA } \\
\text { (R\$) }\end{array}$ & $\begin{array}{l}\text { Valor } \\
\text { Real } \\
(\mathbf{R} \$)\end{array}$ & $\begin{array}{l}\text { Saída } \\
\text { RNA } \\
\text { (R\$) }\end{array}$ & $\begin{array}{l}\text { Valor } \\
\text { Real } \\
(\mathbf{R} \$)\end{array}$ & $\begin{array}{c}\text { Saída } \\
\text { RNA } \\
\text { (R\$) }\end{array}$ & $\begin{array}{l}\text { Valor } \\
\text { Real } \\
(\mathbf{R} \$)\end{array}$ & $\begin{array}{l}\text { Saída } \\
\text { RNA } \\
\text { (R\$) }\end{array}$ & $\begin{array}{l}\text { Valor } \\
\text { Real } \\
(\mathbf{R} \$)\end{array}$ & $\begin{array}{c}\text { Saída } \\
\text { RNA } \\
\text { (R\$) }\end{array}$ \\
\hline $10 / 07 / 2013$ & 15,21 & 15,32 & 26,44 & 25,92 & 0,59 & 0,50 & 155,83 & 157,13 & 54,83 & 54,71 \\
\hline $11 / 07 / 2013$ & 15,80 & 15,56 & 27,54 & 26,68 & 0,55 & 0,61 & 157,71 & 155,92 & 55,14 & 54,62 \\
\hline $12 / 07 / 2013$ & 15,43 & 16,14 & 27,06 & 27,51 & 0,43 & 0,51 & 160,11 & 157,95 & 54,97 & 54,94 \\
\hline $15 / 07 / 2013$ & 15,54 & 15,40 & 27,36 & 26,58 & 0,51 & 0,41 & 163,00 & 160,10 & 54,89 & 54,65 \\
\hline $16 / 07 / 2013$ & 15,75 & 15,62 & 27,87 & 27,22 & 0,49 & 0,48 & 160,24 & 162,86 & 55,01 & 54,89 \\
\hline $17 / 07 / 2013$ & 16,06 & 15,84 & 28,16 & 28,01 & 0,51 & 0,50 & 161,50 & 160,28 & 55,27 & 54,88 \\
\hline $18 / 07 / 2013$ & 16,10 & 16,11 & 28,22 & 27,86 & 0,50 & 0,52 & 164,06 & 161,96 & 56,37 & 55,33 \\
\hline $19 / 07 / 2013$ & 15,88 & 16,16 & 27,93 & 28,06 & 0,50 & 0,51 & 164,36 & 163,19 & 56,16 & 55,93 \\
\hline $22 / 07 / 2013$ & 16,30 & 15,95 & 28,45 & 27,91 & 0,53 & 0,48 & 166,25 & 163,26 & 56,56 & 55,83 \\
\hline $23 / 07 / 2013$ & 16,41 & 16,21 & 28,91 & 28,45 & 0,54 & 0,52 & 166,26 & 166,01 & 56,67 & 56,17 \\
\hline $24 / 07 / 2013$ & 16,39 & 16,53 & 28,94 & 28,85 & 0,54 & 0,52 & 165,04 & 166,02 & 56,63 & 56,12 \\
\hline $25 / 07 / 2013$ & 16,84 & 16,51 & 29,14 & 28,61 & 0,56 & 0,52 & 165,91 & 164,82 & 56,50 & 56,74 \\
\hline $26 / 07 / 2013$ & 16,95 & 16,86 & 29,25 & 29,16 & 0,60 & 0,58 & 165,26 & 165,93 & 56,05 & 56,46 \\
\hline $29 / 07 / 2013$ & 16,68 & 17,02 & 28,90 & 29,30 & 0,64 & 0,57 & 163,17 & 164,80 & 55,69 & 56,40 \\
\hline $30 / 07 / 2013$ & 16,46 & 16,75 & 28,36 & 28,90 & 0,64 & 0,61 & 162,43 & 162,83 & 55,33 & 55,68 \\
\hline $31 / 07 / 2013$ & 16,29 & 16,50 & 28,15 & 28,46 & 0,66 & 0,61 & 164,03 & 162,50 & 55,73 & 55,34 \\
\hline 01/08/2013 & 16,94 & 16,23 & 28,55 & 28,32 & 0,67 & 0,67 & 167,49 & 163,48 & 56,54 & 55,83 \\
\hline $02 / 08 / 2013$ & 16,81 & 16,97 & 28,39 & 28,60 & 0,59 & 0,67 & 167,62 & 166,53 & 56,49 & 56,56 \\
\hline 05/08/2013 & 16,65 & 17,03 & 28,73 & 28,26 & 0,60 & 0,58 & 168,32 & 166,46 & 56,10 & 56,57 \\
\hline 06/08/2013 & 16,28 & 16,65 & 28,35 & 28,73 & 0,58 & 0,61 & 164,78 & 168,47 & 55,49 & 55,90 \\
\hline $07 / 08$ & 16,25 & 16,29 & 29,06 & 28,35 & 0,54 & 0,57 & 163,45 & 164,49 & 55,30 & 55,32 \\
\hline 08/08/2013 & 16,65 & 16,30 & 29,93 & 29,02 & 0,59 & 0,54 & 162,84 & 163,61 & 54,83 & 55,35 \\
\hline 09/08/2013 & 17,08 & 16,73 & 30,90 & 29,89 & 0,59 & 0,58 & 162,13 & 162,66 & 54,52 & 54,85 \\
\hline $12 / 08 / 2013$ & 16,53 & 17,12 & 31,27 & 30,57 & 0,64 & 0,59 & 161,69 & 161,68 & 54,09 & 54,63 \\
\hline $13 / 08 / 2013$ & 16,37 & 16,61 & 31,56 & 31,17 & 0,67 & 0,63 & 163,71 & 161,62 & 54,29 & 54,18 \\
\hline $14 / 08 / 2013$ & 16,95 & 16,35 & 31,60 & 31,50 & 0,68 & 0,67 & 163,34 & 163,56 & 54,15 & 54,49 \\
\hline $15 / 08 / 2013$ & 17,83 & 16,95 & 31,55 & 31,73 & 0,63 & 0,67 & 160,75 & 162,81 & 53,29 & 54,33 \\
\hline $16 / 08 / 2013$ & 17,78 & 17,95 & 32,17 & 31,56 & 0,67 & 0,61 & 160,66 & 160,72 & 53,29 & 53,35 \\
\hline $19 / 08 / 2013$ & 17,83 & 17,89 & 32,35 & 32,23 & 0,68 & 0,68 & 158,63 & 160,96 & 51,83 & 53,30 \\
\hline $20 / 08 / 2013$ & 17,13 & 17,97 & 31,44 & 31,74 & 0,68 & 0,65 & 159,56 & 158,15 & 52,12 & 51,80 \\
\hline $21 / 08 / 2013$ & 17,34 & 17,19 & 31,11 & 31,26 & 0,70 & 0,67 & 157,11 & 159,61 & 51,63 & 52,41 \\
\hline
\end{tabular}

Fonte: Elaborado pelo próprio autor

O grau de predição do preço futuro de fechamento de papéis com alta e baixa volatilidade negociados na Bovespa e na Bolsa de Valores de Nova Iorque usando RNA é significativo. Portanto, de acordo com os resultados atingidos, a RNA aplicada na predição de valores de ações com alta e baixa volatilidade possui uma estrutura adequada e apresenta um resultado satisfatório.

Segundo [8], RNA pode ser utilizada na predição com diversos níveis de sucesso. Uma 
grande vantagem desse modelo é sua capacidade de aprender, de forma automática, apenas com os dados de entrada, sem a necessidade de ajustes futuros. Ao término do treinamento é possível obter resultados válidos, mesmo que haja alguma distorção durante o treinamento. Existem diversos modos de predição, porém essa pesquisa se baseia na predição de valores de fechamentos de ações, também inseridos no contexto de uma série temporal.

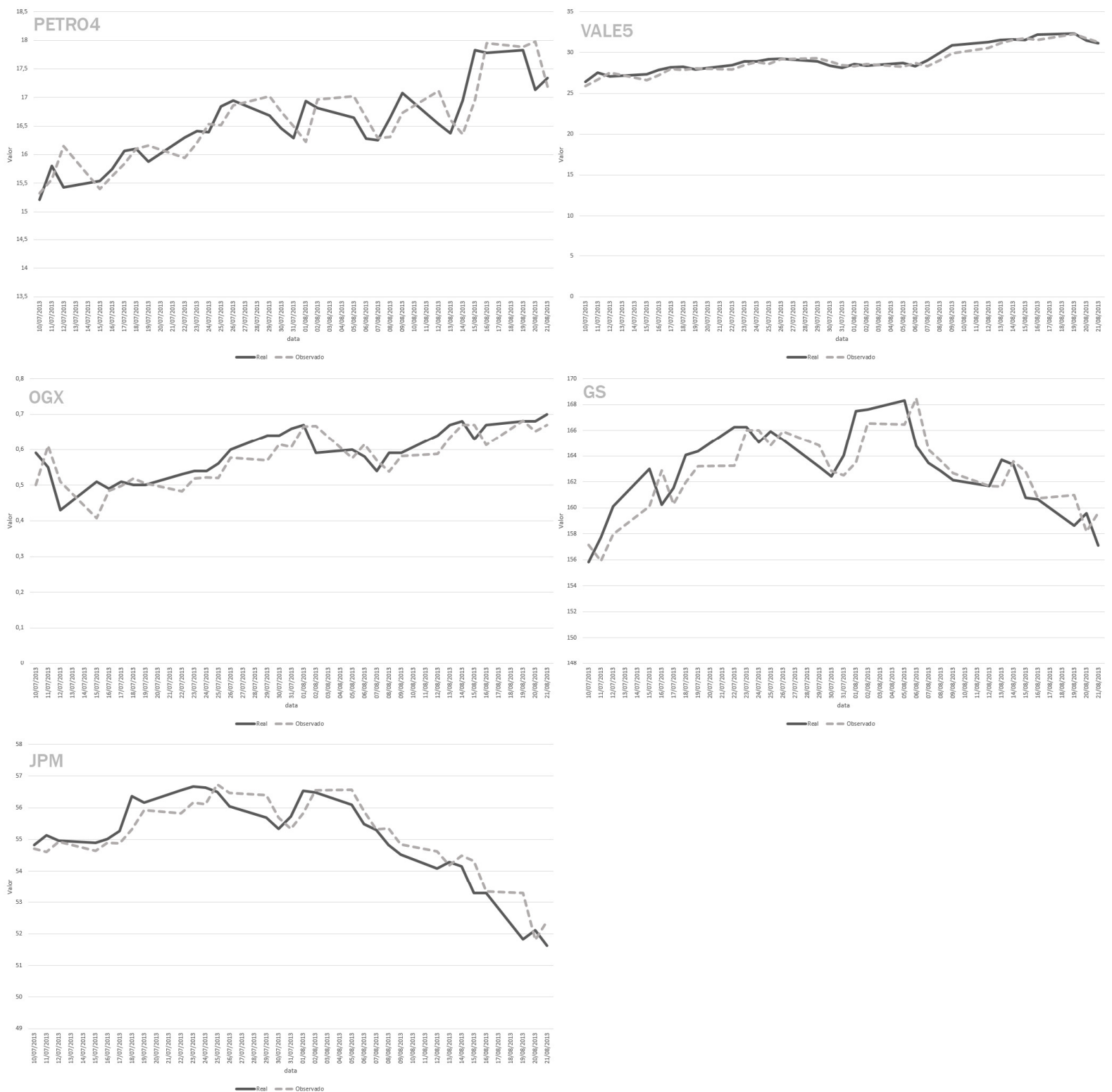

FIGURA 3: Representação gráfica da comparação dos valores diários reais e previstos pela RNA no dia anterior, conforme descritos na TABELA 5.

Fonte: Elaborado pelo próprio autor

\section{CONSIDERAÇÕES FINAIS}

A aplicação da RNA na predição dos valores de fechamento dos papéis negociados nas bolsas de valores mostrou-se válido e o resultado gerado foi satisfatório. Considerando as análises apresentadas é possível observar que a RNA gerou resultados aceitáveis para o problema em questão, tanto na aplicação de um cenário passado quanto aplicada em um cenário real de negociações, com predições realizadas diariamente.

Conclui-se então que a predição dos valores de fechamento de ações de alta e volatilidade utilizando as Redes Neurais Artificiais é possível. Mesmo com a interferência de 
fatores externos, como foi o caso da OGXP3 e da JPM, ambos de alta volatilidade, cenários como esses demonstram a capacidade de predição da RNA proposta nesse trabalho. Portanto pode-se dizer que o resultado da RNA na predição dos valores do preço de fechamento tanto de papéis com baixa volatilidade, quanto na predição das ações de alta volatilidade foi satisfatório.

\section{REFERÊNCIAS BIBLIOGRÁFICAS}

[1] AZEVEDO, Fernando Mendes de, BRASIL, Lourdes Mattos, OLIVEIRA, Roberto Célio Limão de. Redes neurais com aplicações em controles e em sistemas especialistas. Florianópolis: Bookstore, 2000.

[2] BRAGA, Antônio Pádua, CARVALHO, André C. P. L. F., LUDERMIR, Teresa Bernarda. Redes neurais artificiais: teoria e aplicações. Rio de Janeiro: LTC, 2000.

[3] ECONOMATICA. Quem somos. Disponível em: <http://www.economatica.com.br/PT>. Acesso em: 10 set. 2013.

[4] FORTUNA, Eduardo. Mercado financeiro: produtos e serviços. 17. ed. Rio de Janeiro: Qualitymark, 2009.

[5] FREUND, John E. Estatística aplicada: economia, administração e contabilidade. 11. ed. Porto Alegre: Bookman, 2006.

[6] GANDEL, Stephen. Why haven't JPMorgan's legal issues done more to dent the stock? Disponível em <http://finance.fortune.cnn.com/2013/09/27/jpmorgan-stock-rising/>. Acesso em: 05 nov. 2013.

[7] JUNG, Carlos Fernando. Metodologia para pesquisa e desenvolvimento: aplicada a novas tecnologias, produtos e processos. Rio de Janeiro: Axcel Books, 2004.

[8] HAYKIN, Simon. Redes neurais: princípios e prática. 2. ed. Porto Alegre: Bookman, 2001.

[9] HECHT-NIELSEN, Robert. Neurocomputing. New York: Addison Wesley Publ. Co. 1990.

[10] HULL, John C. Fundamentos dos mercados futuros e de opções. 4. ed. São Paulo: Bolsa de Mercadorias e Futuros, 2005.

[11] KOVACS, Zsolt Laszlo. Redes Neurais Artificiais: fundamentos e aplicações. 1. ed. São Paulo: Collegium Cognitio, 1996.

[12] LAKATOS, Eva Maria, MARCONI, Mariana de Andrade. Fundamentos de metodologia científica. 6. ed. São Paulo: Atlas, 2009.

[13] OLIVEIRA, Mauri Aparecido de. Aplicação de Redes Neurais Artificiais na análise de séries temporais econômico-financeiras. Tese de Doutorado. Universidade de São Paulo, 2007.

[14] PINHEIRO, Juliano Lima. Mercado de capitais: fundamentos e técnicas. 5. ed. São Paulo: Atlas, 2009.

[15] RANGANATHAN, Ananth. The Levenberg-Marquardt Algorithm. Disponível em: <http://users-phys.au.dk/jensjh/numeric/project/10.1.1.135.865.pdf>. Acesso em: 23 mai. 2013.

[16] RESENDE, Solange Oliveira. Sistemas inteligentes: fundamentos e aplicações. Barueri: Manole, 2003.

[17] ZÁRATE, Luis Enrique, HELMAN, Horacio, GÁLVEZ, José Maria. Representação e Controle de Laminadores Tandem Baseado em funções de Sensibilidade Obtidos Através de Redes Neurais. Revista Controle \& Automação, Volume 14 no.2, Abril, Maio, Junho 2003. 